\title{
Political Transparency and its effects on the Media: A Study of the Eurocrisis
}

\author{
Maarten Fröling
}

\section{Introduction}

The perceived importance of both transparency and openness has never been greater and more lucid in modern society than they are at the present day. Demanded by the public, and both catalysed and facilitated by the Internet, governments and other institutions have increased their direct communication to their subordinates in a substantial manner. As the exercise and importance of communication increases, accordingly will the effect it has on power and influence. French philosopher Foucault argues that the holder of information has the power to shape and create discourse and thereby influence behaviour and response (1978).

Public relations (PR), specifically political public relations (PPR), has the prime function to inform the general public about important issues regarding the own conduct. This form of, what Heald defined as downward transparency, facilitates that "the ruled can observe the conduct behaviour, and/or results' of their 'rulers"' (2006, p. 27). In situations where there is also a presence of upwards transparency, that is when the superior can observe the conduct, behaviour, and/or results of the subordinate, one speaks of symmetrical vertical transparency (ibid.). Such ideal circumstances would make it impossible for (P)PR to shape "the topic selection and production of news topics" which is in contrast to what decades of research have shown (Froehlich \& Rüdiger, 2006, p. 19; see e.g. Berkowitz, 1993; Cameron, Sallot \& Cutin, 1997; Cohen \& Young, 1973; Curtin, 1999; Curtin \& Rhodenbaugh, 2001; Davis, 2000; Shoemaker \& Reesel, 1991; Van Slyke Turk, 1988). Several studies argue that (P)PR is a political tool to steer "media outlets to communicate specific political views, solutions and interpretations of issues in the hope of gathering public support" for certain policies or campaigns (Froehlich \& Rüdiger, 2006, p. 18; also Neidhardt, 1994, pp. 7-14). As citizens and others alike are heavily dependent on a 'media constructed version of reality', the potential power of politicians in shaping public opinion in favour of their own political gain is enormous (Callaghan \& Schnell, 2001, p. 184).

It is this potential power that the following examines. The main objective is to research whether PPR, in the form of press releases and statements, is able to influence the debates in the media on a certain topic. In other words, it is assessed whether and to what extent 
the media directly adopts the information it is given by a political actor. In order to answer this research focus, a case study format is adopted in the form of the PPR of the European Council (EC) during the European Sovereign debt crisis. The case study topic was chosen because of two reason: first of all, the crisis was given an abundance of consideration by both the median and the EC; secondly, during the Euro-crisis four Member States (MSs) of the European Union were given a 'bail-out' which provided the case study with four, more or less, equal and thus comparable events. Moreover, as Bloomberg accurately phrased, the Euro-crisis is more "a crisis of confidence than really [an] actual situation" making PPR all the more important (The Independent, 2010). The study material consists of EC press realises, official statements and other official documents intended for press. The media material is a collection of six newspapers from three countries: the Irish Independent and the Sunday Independent from Ireland, the Daily Telegraph and the Sunday Times from the United Kingdom, and the Süddeutsche Zeitung and the Zeit from Germany. The newspapers were chosen on the bases of reputation and distribution numbers. The countries were selected on grounds of practical reasons in combination with their different positions and situations in relation to the Euro-Crisis.

For the task at hand, the framing concept is the ideal theory. As Entman writes, "to frame is to select some aspect of a perceived reality and make them more salient in a communicating text" in order to promote a certain perception of reality (1993, p. 52). In other words, "framing essentially involves selection and salience" (ibid.). Hence, the theory will help to examine what perceptions of reality are present in the EC's communiqués and which are present the media outlets'. Framing research in (P)PR is a relative underdeveloped field; in the period between 1990 and 2009, 39 studies were published of which 37 focus on the construction of reality in communication (Lim \& Jones, 2010). The lion's share of these studies focused on business PR, although over the last decade framing research has also largely focused on the Iraq war and the developments around it (see e.g. Hiebert, 2003; Dimitrova, 2005; Dimitrova, 2007; Spielvogel, 2005; Luther, 2005). The inherent difficulty of framing research is that is lacks a "general statement (...) that shows exactly how frames become embedded within and make themselves manifested in a text" (Entman, 1993, p. 51). Therefore, it is important to provide a clear explanation of how one attempts to do research.

This shortened version of the original paper will commence with an explanation of the theory of framing. Second, the methodology and data collection are elaborated on. Third, the frames in the study material are identified and analysed. In the concluding section, the main findings are summarized on the basis of which conclusion will be drawn. 


\section{'Framing' as a means to force Perspective}

The theory of framing is rooted in the assumption that human beings cannot understand the world in all its complexity. It is argued that individuals simplify all sensory information they receive into easier comprehensible conceptions (Heider, 1930; lyengar, 1991; Goffman, 1974). Once these interpretative schemes or frames are entrenched in the memory they are particularly hard to dispel as George Lakoff, cognitive linguist and professor at Berkely University, explains (2002). Because people simplify incoming information, the way in which a message is formulated is of great importance to its interpretation. This is demonstrated by Kahneman and Tversky who examined the systematic behavioural violations of expected responses in the late 1970's (1979). They formulated the prospect theory which argues that the manner in which an issue is framed has a critical influence on perception and thus evaluation, reaction and choice.

The framing of information essentially involves the selection and salience of specific events and issues. Therefore, to frame is to select one or more aspect of a perceived reality and make them more salient in a piece of communication in order to promote a preferred interpretation of the facts at hand. Perhaps the term 'salience' requires some further explanation. To make something salient means to make an issue "more noticeable, meaningful, or memorable to audiences" (Entman, 1993, p.52). The more salient a particular issue is embedded within a text, the higher the probability that the addressees will receive and process the message as it was originally intended by the communicator (Fiske \& Taylor, 1991). The lion's part, if not all pieces of communication, offers one or even several schemata of interpretation of particular events irrespective of the author's intention. Frames "are manifested by the presence or absence of certain key words, stock phrases, stereotyped image, sources of information, and sentences that provided thematically reinforcing clusters of acts or judgements" (Entman, 1993, p. 52). The notion of framing "implies that the frame has a common effect on large proportion of a receiving audience, though it is not likely to have a universal effect on all" (ibid.). Rephrased and turning it around, the effects are personal but a broadly shared reaction is to expected.

Combining the definition of a frame by field expert Entman and the authors Froehlich \& Rüdiger, this chapter views a frame, as (1) providing the diagnosis for a problem, (2) suggesting a solution for this problem, (3) providing a justification or goal for this solution $(1993,2006)$. In addition, in the case of the media reporting, (4) political views either in favour or against the frame are also considered as they have a large influence on the public's evaluation. The combination of the three or four elements leads to what is from now on referred to as a 'position frame'. It is possible that sources only contain certain parts of a position frame or that they state, for example, more than one solution 
or justification. Hence, the research considers all frame elements separately instead of complete frames. In addition to position frames, thematic frames are also considered. This second type focuses on which particular aspects or subtopics of, in this case, the situation around the rescue package are highlighted. The thematic frame will only be used in the analysis of the newspaper articles. The combination of the two teaches us what aspect of the matter is highly debated and what frame elements are highly present.

\section{Methodology and Data Collection}

Preliminary to the quantitative analysis of the newspapers articles, the specific position frames present in the material of the EC had to be identified to allow for comparison between frames. All EC press releases and other relevant documents released between the $19^{\text {th }}$ of January 2010 and the $30^{\text {th }}$ of March 2012 were examined; the period just before the first Greek 'bail-out' and the day the second rescue package for the same country was officially approved by all participating MSs of the EU. This intial collection of a total of 51 pieces of writing was subsequently narrowed down to only include documents with reference to one of the 'bail-outs'. These, so called 'critical discourse moments' or "events likely to change the course of the whole debate and generating high media attention" took place on and around the $10^{\text {th }}$ of May, 2010, the $21^{\text {st }}$ of November 2010, the $16^{\text {th }}$ of May 2011 and the $21^{\text {st }}$ of July 2011 (Froehlich \& Rüdiger, 2006, p. 19). It was one these dates that Greece, Ireland and Portugal officially received their rescue package for the respective first, or in the case of Greece, also second time. The selected documents were read several times and the frames were subsequently identified. A detailed discussion can be found in the original paper.

For the analysis of the media frames a number of articles were selected just before and just after the announcement of the financial aid to the particular MS. It depended on the particular newspaper on which date the first article was selected as some newspapers started and stopped writing on the issues relatively early whereas for others is was quite the opposite. For the Sunday newspapers at least one week before and one week after were considered. All articles which mentioned the particular 'bail-out' within the selected time period were analyzed. Each article was read at least two times to correct for possible mistakes made the first time round. Every encountered thematic and position frame (element) were given a unique code. The sources of quotations containing frame elements were also coded. All these variables were then merged by defining them as a set of 'multiple responses'. A set was defined for thematic frames, positions frame elements, EC frame elements and quotations. 


\section{Media Frames: Results}

A total of 383 articles were read divided over the earlier mentioned six newspapers for the purpose of identifying frames. The subsequent part of the shortened version of the paper discusses the media frames in a case by case format in the chronological order of events. In each study, the position frames identified in the media are compared to that of the EC. In addition to examining the frames, it was also researched which actors were quoted most often in combination with a frame element, and how important quotations were in support of the particular EC Frame. The most important findings are discussed below.

\section{Greece 2010}

Between the $25^{\text {th }}$ of April and the $16^{\text {th }}$ of May a total of 117 articles were selected and subsequently analyzed. One out every five articles focuses on the 'Financial Market' while roughly every eighth article considered either the 'European Safety Mechanism' or the 'German Politics'. The actual 'Content of the Rescue Package' was the main focus of $12 \%$ of the articles. All of the phrases above between the inverted commas are thematic frames as explained in an earlier section. In sum, a total of 23 such themes were encountered of which a large number was only found in a small percentage of source material indicating a large diversity in the issues highlighted within the newspapers.

A little over three-fourths of the selected articles contain one or more elements of a position frame and will therefore be considered for the rest of the analysis. In roughly halve of these cases, at least on the element of the above distinguished European Council frame were found. However, there is a large diffusion of the elements over all the articles as the complete EC frame is retrieved in none of the articles and practically all contain only one element. The most popular frame element is the fear that the rescue package will not prevent contagion to other MSs. Justifications provided by the EC frame are second and third although with a considerable lower relative presence. Comparing the newspapers and countries teaches us that particularly the Irish and English newspapers have a relative high percentage of articles with negative political views towards the rescue package. Across the board, Angela Merkel is quoted most often and the Bundeskanzlerin was also very important in promoting the EC frame as almost halve of the articles with this same frame contain one or more of her quotes.

When the factors time is taken into careful consideration a more representative image of the reporting arises. As stated earlier, the rescue package was officially announced on the second of May 2010. Between that date and $5^{\text {th }}$ of May, almost halve of all articles containing the EC frame were published. In fact, on the $2^{\text {nd }}$ of May $72,2 \%$ of all published articles that day contained one or several EC frame elements. The next day even all articles 
hosted Council frame elements. On the fourth is was $60 \%$ and on the fifth $38,5 \%$. The following days, these numbers were significantly lower until the announcement of the ESM on the $9^{\text {th }}$. On that day, again all articles contained EC elements. What is more, within the second and fifth, three-fourths of all articles with positive opinion towards the measures were written. In fact, $72,2 \%$ of all negative points of views were still to be published by the fifth. All together, there seems to be trend which suggests that the EC frame is overrepresented in the days around the announcements. In the following cases this will be further tested.

\section{Ireland 2010}

For the study of the Irish case a total of 140 articles were read. As two of the selected papers are of Irish origin, it is not surprising that these newspapers provided the majority of the material with 65 articles. Different from above, the actual 'content of the rescue package' was the most discussed thematic frame in one out of every five articles. Other popular themes were in this case 'Irish Politics', 'Financial Markets', and the 'EU approach to the crisis'. In line with these results, and similar to above, roughly three fourths or 107 of the selected articles contained identifiable position frame elements. However, a significant lower amount of articles were found in which the EC frame elements were also retrieved. In this case, less than a third of the 107 articles contain such elements. Interestingly enough, a comparison between the countries shows that the Irish newspapers have the highest percentage of articles in 'support' of the EC frame. The German newspapers have the lowest amount of such articles and also have more critique. The English newspapers are indifferent, publishing both articles with negative and positive political points of view without one being dominant. Similar to above, in non of the writing the EC frame was retrieved in its entirely. Twenty-four of the 29 articles host only two or even one element in line with a more or less even distribution across two the categories. The EC frame elements are only represented in very small percentage of the articles. This is real surprise considering that 57 articles contained negative point of view towards the rescue package. A total of $34,6 \%$ of the selected material expresses a concern that the measures taken are not able to prevent, or have taken way the fear of, contagion. Also similar to first rescue package, quotes were of particular importance in the advancement of EC frame elements into the newspapers. The European Council, the Commission and individual members of the European Council contributed largely to the transposition of the EC frame into the newspapers. Nonetheless, the most frequent quoted actors were the financial institutions with a one-third chance that the citation was theirs. 
When time is taken into consideration as it is done above, a similar though less dominant trend appears. The rescue package was officially announced on the $28^{\text {th }}$ of November. Nonetheless, the Irish request and the EC's reaction upon it took place a week earlier on the $21^{\text {st }}$. On this day and the one that followed almost halve of all articles containing element of EC position frame were published. On the $29^{\text {th }}$ and $30^{\text {th }}$ another third was written. In other words, around $75 \%$ of the articles that contain element of the EC frame were released within two days of the respective announcement. It is also on these first two days that $36,4 \%$ of the articles with positive opinions towards the actions was published. Moreover, between the $28^{\text {th }}$ and $30^{\text {th }}$ another $54,5 \%$ was made public. However, in contrast to the previous case, a lot of negativity was also written on these days. On the same days, just over halve of all articles contacting such contest was released. Additionally, the articles in support of the EC are less dominant on the specific days. On the $21^{\text {st }}$ a respective $23,1 \%$, and on the $22^{\text {nd }}$ a total of $50 \%$ contained Council elements. The week later it was only $25 \%$ followed by $40 \%$ the following day. Therefore to conclude, the majority of EC 'supporting' articles were found on the respective day of the publication of the frame. However, they are less dominant in the Irish case than they were during the 2010 Greek 'bail-out'.

\section{Portugal 2011}

The study of media frames in the case of Portugal is somewhat troubled by the fact that a significant lower number of articles was written on the issue. The Sunday independent, for instance, did not publish a single piece of relevant writing on the Portuguese 'bail-out' within the examined period. The missing of relevant sources is due to the speculation of a second rescue package for Greece and the re-negotiations of the Irish 'bail-out' which both largely dominated the news reports. All the same, 21 of the 44 selected articles contained positions frames and twelve of those had EC frame elements. The German newspaper the Süddeutsche Zeiting has the EC frame present in all of its articles with position frames. However, the Germans are also ranked high when it comes to negative political views. Moreover, these types of political views are far more dominant than their direct opposite. Almost all pieces of writing of the Irish newspapers contained position frames. The prolonged period of time to correct the budget deficit, in particular, received considerable attention. The low interest in the Portuguese rescue package not only affected he number of articles, it also resulted in fewer quotations. Out of the 10 articles with quotations, no more than one carried quotations containing EC frame elements. In all ten articles, negative elements towards the rescue package could be found. Positive frame elements, on the other hand, are found in no more than four articles. The articles in which these interpretations were found contain quotes by Commission President Barosso and the Portuguese Prime Minister 
Although the precise details of the Portuguese 'bail-out' were officially released on the $16^{\text {th }}$ of May 2011, the majority of the plans became public on the $4^{\text {th }}$ of the same month. The occurrence of two events, in combination with the low amount of articles containing position frames, makes it bold to do an analysis accounting time as a factor. Therefore, less valuable will be attached to the following analysis in the overall conclusion(s). Similar to the case studies above, the frame elements of the Council are found most often in articles released on the same day as the official statements and just after. On both the fourth and the $16^{\text {th }}$ of May, two articles containing such content were written while on the fifth another three were published. In between these dates only $16,7 \%$ of such articles were found while the articles on these dates accumulate to a total of $58,3 \%$. On the fourth $66,7 \%$ of all articles contained Council frame elements, on the fifth it was $100 \%$ and on the $16^{\text {th }}$ it was $66,7 \%$ once again. Negative political views were only found in $33,3 \%$ to $50,0 \%$ of cases. Therefore, one can carefully conclude that the Council's frame was dominantly present in the newspapers on the discussed dates.

\section{Greece 2011}

For the examination of the media reporting of the second Greek 'bail-out' 82 articles were selected. Exactly 60 of these articles contained position frames. Similar to the Irish study, the content of the rescue package was the most discussed theme with $43 \%$ of the material. Also corresponding to the earlier discussed situations, the themes 'The Financial Markets' and 'EU approach to Crisis' were most frequent. The most discussed frame element is the contribution of the private sector with a presence in 26 articles. Second is a default by Greece on its debts while the new lower interest rate is third with 16 articles. Overall, the Council's frame scores high with 4 of its elements in the top eight. The categories 'Fear of Contagion', 'No solution to structural Problems' and 'Haircut' complete this ranking with between 13 and 15 articles each. The result of the thematic frames analysis gave a good indication as to how many articles would contain the Council's frame. 40 pieces of writing have at least one element of the 'Council Frame'. The result is the highest percentage among the four studies with $66,7 \%$. The Irish newspapers have the highest relative amount of such articles and the English broadsheets the lowest. Similar to the first two examinations above, direct references are responsible for the majority of the frame elements of the Council. Overall, however, they are only present in 22 or 36,7\%. Sarkozy and Merkel are accountable for the majority of almost halve of these articles with quotes in six and four articles.

Despite the high presence of the Council's Frame, negative frames can be found in just over halve of 60 articles. In $51,7 \%$ of cases one or more negative elements are found. As mentioned above, the most often mentioned critic, is the (continued) fear of contagion to 
other Eurozone countries followed by the lack of a structural solution and the opinion that it only buys time. The believe that the approach to the crisis is false is found at the fourth place. As is to be expected, especially the financial institutions and other claimed experts express themselves negatively towards the package. Positivity towards the measures is, just as in the other studies, very scarce. Merely one article contains positive elements.

The trend detected in the previous cases continuous retrieved in the current study. Similar to the previous instances, the majority of the Council Frames were published on the date of the official release, the $21^{\text {st }}$ of July and the next couple of days. In fact, on the first two days after the disclosure $60 \%$ of the articles containing the Council were published. Having stated that, on the same days $51,6 \%$ of the 60 articles was also published. Therefore, as a means of providing perspective, 2 out of three articles published on the $21^{\text {st }}$ contained elements of the Council Frame. On the $22^{\text {nd }}$ no less than $87,5 \%$ of all articles contained such content. Negative statements were presents in $46,6 \%$ and $50 \%$ of cases although these did take the overhand in the next couple of days.

\section{Discussion and Conclusion}

In a changing world in which transparency and openness will continue to increase in importance the above set out to examine whether PPR is able to influence or shape the media discourse on certain issues. In the light of Foucault's view that the holder of information has the power to influence and shape discourses, this chapter thus viewed communication and transparency as a (political) tool for the fulfilment of certain objectives. The research adopted a case study format selecting the European sovereign debt crisis, or Euro-crisis, as its main objective. The 'bail-outs' of Greece, Ireland and Portugal in 2010 and 2011 provided four comparable events for the analysis. The analysis itself consisted of comparing the content of the press releases and other documents of the European Council to that of the media. For the examination of the latter, a total of six newspapers was selected from Germany, the United Kingdom and Ireland. With the help of the concept of 'framing' the source material were assessed on the basis of position and thematic frames. Making use of the work of Entman, Froehlich and Rüdiger with regard to position frames it was decided to focus on the problem definition, suggested solutions and the justification and goals for these solutions. Additionally for the analysis of the media a fourth element was added, namely the political view or arguments in favour or against. The thematic frame, as the name suggests, refers to the main theme of the media articles and provided a good indication of the most discussed topics. 
The analysis of the four events resulted in the appearance of an interesting trend confirming Foucault's argument. In all cases, although in some to a greater extent than in others, it was found that the 'Council Frame' was published most often on the same day the press release was published and the days directly following. However, the effect extended beyond the mere publishing of the elements, it was often the case that EC frame elements were present in the majority of the articles published on those days. Additionally, articles containing negative points were in most published a couple of days after the official announcement providing the EC with a 'dominant position' in the news reporting during the initial days. In the promotion of the Council frame elements quotations played an ever important role. Especially Angela Merkel contributed largely to this result. In addition to this repetitive trend, one could also observe some changes in the media reports. Initially, the focus, that is the thematic frame, was mostly on political issues and other matters directly relating to the rescue package but not the content of the package itself or the strategy of the EU. The media gave more and more attention to the content and it also became more critical which is reflected in the rise of quotations from financial institutions. The latter generally did not believe that the packages would work and the greatest fear throughout all four cases was that of contagion to other MSs. When seeking to find explanations for the found results, most of them seem rather logical. "Newspaper and media outlets alike presumably need time to assess the impact of what it being stated and done before they can write critical analyses". Nonetheless, the apparent time gap that is resulting from this creates a vacuum of which politicians in this case, the EC, know how to make use of. However, one cannot concretely value the effectiveness of PPR based on these trends. Therefore, it would be worthwhile to invest time and research into the development of instrument that could accurately measure this. Moreover, research on a larger scale would also be an asset to further research. In the study above only limited amount of media outlets and one type was assessed. Therefore, a larger study encompassing multiple events, outlets and institutions would therefore be encouraged. 


\section{Bibliography}

Berkowitz, D. (1993). Work rules and news selection in local TV: Examining the businessjournalism dialectic. Journal of Broadcasting \& Electronic Media, 37, pp. 67-81

Callaghan, K. \& Schnell, F. (2001). Assessing the Democratic Debate: How the News Media Frame Elite Policy Discourse. Political Communication, 18, pp. 183-212.

Cameron, G. T., Sallot, L. M. \& Curtin, P. A. (1997). Public Relations and the production of news: Critical review and theoretical framework. Communication year book, 20, pp. 111-115.

Cohen, S. \& Young, J. (1973). The manufacture of news, deviance, social problems and the mass media. Newbury Park. Sage.

Curtin, P.A. (1999). Re-evaluating public relations information subsidies. Market-driven journalism and agenda-building theory and practice. Journal of Public Relations Research, 11, pp. 53-90

Curtin, P.A. \& Rhodenbaugh, E. (2001). Building the news media agenda on environment: A comparison of public relations and journalist sources. Public Relations Review, 27, pp. 179-105

Davis, A. (2001). Public Relations, news production and changing patterns of source access in the British national media. Media Culture \& Society, 22 (1), pp. 39-6o.

Dimitrova, D. V. \& Strömbäck, J. (2005). Missing accomplished? Framing of the Iraq war in the Elite Newspapers in Sweden and the United States. Gazette: The International Journal for Communication Studies, 67 (5), pp. 399-417.

Dimitrova, D. V. \& Connolly- Ahern, C. (2007). A Tale of Two Wars: Framing Analysis of Online News Sites in Collation Countries and the Arab World During the Iraq War. Howard Journal of Communication, 18 (2), pp. 153-169

Entman, R. M. (1993). Framing: Toward Clarification of a Fractured Paradigm. Journal of Communications, 43 (4), pp. 52-58

Foucault, M. (1978). Security Territory, Population. In lectures at the College de France 1977-1978. Retrieved from http://www.scribd.com/doc/7861907/Foucault-security-territorypopulation

Froehlich, R. \& Rüdiger, B. (2006). Framing political Public Relations: Measuring success of political Communication strategies in Germany. Public Relations Review, 32, pp. 18-25

Goffman, E. (1974). Frame Analysis: An Essay on the Organization of Experience. Cambridge, Massachusetts. Harvard University Press.

Heald, D. \& Hood, C. (2006). Transparency; The Key to better Governance? Oxford: Oxford University Press.

Heider, F. (1930). Die Leistung der Wahrnehmungssystems. Zeitschrift für Psychology, 114, pp. 371-394. 
Hiebert, R.E. (2003). Public Relations and propaganda in framing the Iraq war: a preliminary review. Public Relations Review, 29, pp. 243-255.

Kahneman, D. \& Tversky, A. (1979). Prospect Theory: An analysis of Decision of Risk. Ecometrica, 47 (2), pp. 263-292.

Lakoff, G. (2002). $2^{\text {nd }}$ Edition. Moral Politics: How Liberals and Conservatives Think. London Chicago. The University of Chicago Press.

Lim, J. \& Jones, L. (2010). A baseline summary of framing research in public relations from 1990 to 2009. Public Relations Review, 36, pp. 292-297

Lyengar, S. (1991). Responsible? How television Frames Political Issues. Chicago, London. The University of Chicago Press

Luther, C.A. (2005). Framing of the 2003 U.S. - Iraq war Demonstrations: An analysis of News and Partisan texts. Journalism \& Mass Media Quaterly, 82 (1), pp. 78-96

Schoemaker, P. J. \& Reese, S. D. (1991). Mediating the message: Theories of influence on mass media content. New York: Longman.

Spielvogel, C. (2005). "You know where I Stand": Moral Framing of the War on terrorism and the Iraq War in the 2004 Presidential Campaign. Rhetoric \& Public Affairs, 8 (4), pp. 549-570

Van Slyke Turk, J. (1998). Public relations' influence on the news. In R.E. Hiebert (Ed.), Precision public relations (pp. 224-239). New York: Longman 